\title{
The meaning of compassion fatigue to student nurses: an interpretive phenomenological study
}

Kirsten Jack

\begin{abstract}
Background: Compassion fatigue is a form of occupational stress which occurs when individuals are exposed to suffering and trauma on an ongoing basis. The purpose of this study was to explore the experiences of compassion fatigue among student nurses following their first clinical placement in a UK health care setting during 2015.

Methods: The aim of this study was to explore students' thoughts and feelings about compassion fatigue using reflective poems as a source of data. An interpretive phenomenological approach was taken using a purposeful sampling strategy which aimed to explore in depth meaning of the concept as experienced by the students.

Results: From this study it is clear that students experience compassion fatigue and this has a psychological effect on their wellbeing and ability to learn in the clinical practice setting. Reflective poetry writing enabled articulation of feelings which were at times negative and linked to the student's status as a novice nurse.

Conclusions: Students experience compassion fatigue and educators need to find ways to provide support in both clinical and university settings. Positive practices such as shared reflection and the use of creative teaching methods might be beneficial, to support exploration of feelings, build resilience and effective ways of coping.
\end{abstract}

Keywords: Clinical placement, Compassion fatigue, Interpretation, Phenomenology, Poetry, stress, Student nurses

\section{Background}

Compassion fatigue is a term associated with nursing practice and is a form of occupational stress which has been linked to burnout and vicarious traumatisation [43]. Nursing is a stressful occupation and the most common stressor is heavy workload, which means that nurses are unable to carry out their role in the way they would like [39]. Subsequently there is incongruence between the nurse's ideal and the actual reality of nursing practice, leading to dissatisfaction and frustration with the role. As student nurses do not hold the same level of responsibility as qualified staff, it could be argued that they are not exposed to as much stress, although having student status is stressful in itself [37]. In the UK student nurses spend half of their programme experience in a clinical area and it is these placement experiences that can cause a huge amount of stress, which can sometimes

Correspondence: k.jack@mmu.ac.uk

Faculty of Health, Psychology \& Social Care, Manchester Metropolitan

University, Brooks Building, Bonsall Street, Manchester M15 6GX, UK lead to students discontinuing their programme of study [16]. The emotional nature of nursing can cause a large amount of stress to student nurses [21] and the socialisation process can have a particularly negative effect on their emotional well-being [32]. Student nurses suffer financial hardship which might be linked to the current bursary arrangements, which might lead some to feel the need to engage in part time work to supplement their income [40]. This situation can lead to less study time and more personal stress. The financial situation for UK student nurses might be set to worsen, due to the Department of Health (DH) announcement regarding the withdrawal of the student nursing bursary from 2017 [8]. The implications of this are as yet unclear although the change might have a negative outcome for student nurses [40]. In addition to finance, the amount of stress experienced might relate to the learning stage of the student. Rudman \& Gustaffson [42] suggest that the second year is the most stressful for student nurses although the first clinical placement has also been identified as being 
particularly problematic, as students worry about making mistakes and causing harm to patients at this early stage of their learning [26]. The first clinical placement can cause high levels of stress which negatively impacts on learning [24].

Compared to stress the concept of compassion fatigue, described as one form of occupational stress, is more recent, and has been studied primarily in non-nursing groups [51]. Compassion fatigue was first described in a nursing context by Joinson [23] who suggests it is a response to the large amounts of stress, and occurs when nurses witness suffering, illness and trauma on an ongoing basis. She describes compassion fatigue as 'emotionally devastating' (p. 116), an unavoidable part of care giving, and the caregivers personality type can increase susceptibility to it. Figley CR [10]: 7) describes compassion fatigue as the 'natural consequent behaviours and emotions resulting from knowing about a traumatising event experienced by a significant others-the stress resulting from helping or wanting to help, a traumatised or suffering person'. Sabo [43] describes a number of key triggers of compassion fatigue including, the nurses personal characteristics, previous exposure to traumatic events, response to the stressor and the work environment. There are many signs of compassion fatigue including sadness, avoidance, detachment and changes in beliefs and assumptions [43]. Based on these descriptions, it would seem that student nurses are susceptible to compassion fatigue during their educational experiences. This could potentially have a detrimental effect not only on the ability of the student nurse to learn in the clinical environment, but to their physical and psychological health.

It is important that student nurses have happy and positive learning experiences, not only for the sake of their own health but because a clear link has been identified between staff wellbeing and effective patient care [31]. If student nurses suffer from compassion fatigue then this could have negative implications not only for themselves but for others. Michalec et al. [34] suggest that being a student affords some protection against compassion fatigue although there is potential for it to develop following transition to qualified nurse. However, in the clinical area students still witness the same amount of trauma and suffering as qualified staff. Further, students might be required to provide more of the personal care and work more closely with the patient than other members of the team. Therefore it would seem that student nurses are at risk of suffering huge amounts of stress during their education although little is known about their experiences of compassion fatigue.

\section{Methods}

\section{Aim}

The overarching aim of this work was to explore student nurses experiences of compassion fatigue using student authored reflective poems as a data source. It is important to understand students' experiences of practice so that they can be supported appropriately both in clinical and academic settings. This has the potential to positively affect retention, promote the health and wellbeing of the student group and support effective patient care provision. Further, sharing experiences of practice can support development of the bond between the student and educator and helps develop constructive relationships, which are grounded in an enhanced understanding of the student's lifeworld [20].

\section{Design}

I used an interpretive phenomenological approach to explore how our students described and understood compassion fatigue on a personal and professional level. This style of phenomenology is based on the belief that the way to understanding is through interpretation, which in turn is based on our history, or, what has happened to us in the past [17]. Heidegger [17] stated that our 'being in the world' is covered up, and phenomenology is required to uncover what is happening to us. Phenomenology is not merely concerned with the description of thoughts and feelings but is an attempt to uncover the meaning behind what is actually said [30]. Naturally, the interpretation will rely on the researcher's interpretative lens and as Finlay [11] suggests, the research is a combined product of the data and also the relationship between the informants and researcher. This leads to a combined interpretive 'truth' based on words and feelings. This style of phenomenology is in contrast to the Husserlian approach, which seeks to find an untainted 'truth' which is free from the researcher's previously held thoughts and assumptions about the subject being researched. Husserl, originally a mathematician, was concerned with truth which was free of presupposition [19]. However, there is great potential to reach different understandings of a phenomenon when we combine our own 'prejudice' about a subject with the thinking of another person. In this context, prejudice is used in a positive way, and leads to a new ways of understanding [14]. This process can lead us to discoveries which might never be made had we chosen to bracket out our previous thinking about the phenomenon. Dahlberg et al. [6] describes the interpretive process as the whole-the parts-the whole'. As researchers we begin with the 'whole' of our initial understanding, which is then exposed to the 'parts', for example, lines of the students' poems. Then, a new 'whole' is revealed based on what we knew already, combined with the informants thinking on the subject.

In keeping with this approach, it was important that I exposed my understanding of compassion fatigue to make it clear how my interpretation of the data was 
reached. This process adds to the credibility of the research, as the reader is exposed to the context surrounding the interpretation, as they are privy to the thoughts of the researcher [5]. Figley CR [10]) describes compassion fatigue as a sudden response accompanied by feelings of helplessness, confusion and isolation from others and I suggest that my own experience relates most closely to this description.

\section{My prior experience}

As a student nurse the most satisfaction I gained was through talking to patients and trying to make emotional connections with them. As a third year student nurse, during one clinical placement on a female medical ward, an elderly woman had been admitted following a myocardial infarction. She was accompanied by her husband and it seemed clear to me that their relationship was very loving and caring. He seemed devoted to her and the love between them was obvious. I came to know them well during her stay and when she recovered a date was set for discharge. However the day before she was due to be discharged she suffered a cardiac arrest and died. I was shocked and overwhelmed by this experience, not least because it seemed unexpected. What upset me most was the thought of her husband and after someone had broken the news to him, his face was that of a lost man, bewildered and confused. He came onto the main ward to see his wife and I was standing close by. I spontaneously gave him a hug and started to cry, something that was not accepted by my assigned educator, who suggested I went off the ward and got a drink for myself. I was coming to the end of my preregistration education and was physically and mentally exhausted. Following this event I felt confused, helpless and heartbroken; I had not known what to do at that time, words seemed insufficient and I felt very distressed.

\section{Poetry as data}

Reflective poetry, written by student nurses, was used as data in this study. Poetry, both published and student authored, has been used in various ways and across many disciplines to explore students experiences, for example, Nursing [3, 25], Sports Coaching [48], Teacher Education [47] and Medicine [12]. Student authored poetry has been used as qualitative data in nursing research $[20,25]$ and when used in this way, supports our understanding of the individual lifeworld of another. Indeed Rolfe \& Gardner [38] call for nursing research which values the individual nature of others and it is often the difference between informants' stories which is interesting, rather than what is similar. Poetry is an effective way to tell unique stories of experiences and supports exploration of feelings, some of which might not usually be considered [47]. Some students might worry that they are not creative and find poetry writing a difficult task; it is important that educators do not judge the quality of the poems written and accept all as having value [48]. However poetry writing enables feelings to surface in ways, such as reading published poems, might not [20]. Poetry writing encourages the use of metaphor which enables students to explore ideas in ways they might not usually do [44]. It can support understanding of the patients point of view and help the writer see things in a more holistic way [7]. Further, it can support self-development and exploration [35] making it a helpful way to consider nursing values and how they relate to the self. Therefore when exploring the phenomenon of compassion fatigue, reflective poems were considered a rich source of data.

\section{Sample}

A cohort of 42 nursing students on the BSc (Hons) Adult Nursing programme at a UK university were asked to write and submit poems relating to the concept of compassion to the 'Caring Words' website in 2015. This was not related to their assessment but as part their directed study learning during the module. The website www.caringwords.mmu.ac.uk is a dedicated online community where students can read poems written about practice by their nursing peers, and post poems of their own. The community was developed to reduce the isolation students feel when exposed to difficult clinical practice issues. By reading the poems written by others, students feel less alone when they read that other students might be experiencing the same or similar feelings to themselves.

Minimal guidance about poetry writing was given to the students, although it was suggested that the poems could be written in first person or 'from a distance', using the voice of the patient, or as if telling a story as an observer. Students were given a period of 2 weeks to complete this exercise and this was preceded by a discussion of the benefits of expressive writing and the multiple creative ways in which nurses can reflect on practice issues. Some students became concerned about the quality of their poems although were reassured that the exercise was about the reflective process they followed during the writing of the poem, rather than the finished product. Viewing the poems on the website, written previously by their peers, supported them in writing their own work. After the 2 week period, the students meet and discuss their poems in a small group, facilitated by an experienced educator. This has been shown to be an effective way to explore and reflect upon practice issues.

On review of the work submitted, rather than focus on compassion, it was clear that some poems explored the 
difficulties of caring and I interpreted these works as reflecting the concept of compassion fatigue. This was not entirely an unexpected finding as I had not directed the student group in a particular way, therefore they were free to interpret the brief how they liked. I wanted to use poetry writing to uncover the realities of practice and it was clear that the students did not always experience compassion in positive ways. Some of the poems revealed stressful events and experiences relating to their practice as a student. For me as an educator, I felt it was beneficial to know about these experiences, based on the belief that if I can understand how students are feeling, I am better positioned to provide support and subsequent effective interventions. All four of the poems selected for this study were written by female students who were coming to the end of their first year of the undergraduate nursing programme. The poems were purposively chosen as they were the ones most representative of the concept of compassion fatigue. The students had been exposed to one clinical placement at the time of writing the poems. The age range of the sample was $18-30$ years of age.

\section{Analysis}

As discussed earlier, it is often the differences between experiences which hold the most interest, rather than the similarities or themes which cut across all of the data. With this in mind, the poems were analysed as individual works rather than thematically. Fragmenting poems to ease the process of analysis, although tempting, would not do justice to the individual pieces and in agreement with Shapiro and Stein [44]: 176) might be considered 'aesthetic murder'. Therefore the poems were individually analysed and in line with a phenomenological approach were considered using the hermeneutic circle. Heidegger [17] suggests that 'In the circle is hidden a positive possibility of the most primordial kind of knowing' and this form of analysis operates on multiple levels. For example, lines of a poem are considered against the backdrop of the whole piece of work, whole poems are analysed in relation to the parts, and this goes on in a back and forth motion until a different understanding of the phenomenon is reached. Often, perspectives can only be understood and interpreted against the backdrop of the whole situation. Therefore it is important to work in a circular motion, whole-parts-new whole, until understanding is gained.

\section{Results}

Using the description provided by Sabo [43] the data revealed three areas which were indicative that the students in this study were suffering from compassion fatigue. A feeling of sadness was revealed through all of the poems, which conveyed psychological distress and unhappiness and at times this was linked to the clinical environment and attitudes of other staff. Some 'key triggers' for compassion fatigue [43] were evident in the poems such as the personal characteristics of the nurse and the clinical environment. The themes were as follows:

- Psychological distress

- Personal characteristics of the nurse

- Work environment/attitudes

The themes were revealed in all of the data to some extent. Therefore the poems are presented entire, under their original headings and preceded by a discussion of the multiple themes located within.

\section{More}

The first poem, 'More', explores the experiences of a student nurse caring for a frail older man who had been admitted into hospital. She describes her heartache and feelings of sadness for someone who seems despondent and unable to tolerate further treatment, as described by the line; 'I'm too old; I can't take it, please no more'. The environment and attitudes in the care setting seem to be working against the desires of the patient and student nurse. She has been exposed to a traumatic situation which she finds difficult to cope with and feels unable to help.

In he came looking tired and frail

A little old man of 97.

As he peered up into my eyes, it was clear to see. He was not happy or hopeful of what would come. What would be?

He spoke the words, "no more, no more" "I'm too old; I can't take it, please no more". As my eyes welled up and my heart ached. I thought of this man and what he would await. Would it be good news? Would it be bad? It was unclear

But he needed support, a strong shoulder to show his fear.

I stood by him, held his hand, smiled and he starred.

He looked at me, defeated as if no one was even there.

I did what I could, but it didn't feel enough.

I wanted to take away his pain but it's tough. This old man didn't want to be prodded and poked. It was a lot to take in, it was hard and I choked. Out he went looking the same as before.

I just wish I could have done more.

\section{Live in the sky}

The following poem explores the death of an infant, an experience which has caused distress to the student 
nurse who uses imagery and metaphor to describe her feelings. There is reference to 'The wave of emotion' and seeing the infant made her 'heart melt'. She describes explicitly her 'pain and heartbreak' and returns to metaphor to describe her current feelings which she suggests are 'raw'. The work ends more positively as she describes her pride and her feeling that the child will be cared for beyond death.

The wave of emotion that I felt

Seeing you for the first time, made my heart melt,

The pain and the heartbreak it was intense,

With all the studying, it just didn't make sense,

Nothing could have prepared me for what I saw,

Until this day my feelings are raw,

A life taken away so sudden, but what is done is done, You would have made a brilliant son,

Your little body so tiny and small,

"Are you okay?" The nurses would call,

Everything around me just like a cloud,

Seeing you made me sad but also proud,

Now a little angel you can fly,

To be taken care of and live in the sky.

\section{Professional widow}

The next poem 'Professional Widow' describes a traumatic situation as suggested by the early line 'Your fretful face and wistful cries'. There is reflection on the personal characteristics of the student nurse inherent throughout the poem. She begins by describing her distress; she is tearful and heartbroken by what she is witnessing. However she describes her ability to provide humour, 'I made you laugh...' and suggests a show of strength; 'To fight your corner, carry you'. There is a sense of inadequacy in that she suggests the need to be stronger than she is able, including the need to keep her feelings at 'arm's length'. However, this way of being is not authentic for her as she suggests the need to '.....just pretend, Be your protector, not your friend'.

Our first day was something shared

You were brave but felt so scared

Your fretful face and wistful cries

Sent tears cascading from my eyes

I made you laugh to ease your pain

To see you smile then watch it wane

I'll be the one that helps you through

To fight your corner, carry you

To find exactly what to say

To promise it will be $\mathrm{OK}$

It broke my heart to watch you suffer

"Chin up chick, you must get tougher"

Came the cries of camaraderie

"Concentrate now, that's an artery!"
I sought advice and found the strength

To keep my feelings at arm's length

Respect your boundaries, just pretend

Be your protector, not your friend

And leave you in your hour of need

Understand please, Just concede

I must be strong and let you go

To stand alone and beat your foe

But I will think of you today

And pray your fears have gone away

Forever in my heart \& verse

You shaped my future as a nurse

\section{Professional face}

In the following poem, 'Professional Face', feelings of frustration are evident and relate to the need to wait for a qualified nurse to dispense drugs to a patient in pain. The situation unfolds over a twenty minute time period and it becomes evident that the student nurse will be required to stay late. The poem has a feeling of anger running through it, not least because of the way the student nurse is spoken to by qualified staff members. The phrase 'student aka skivvy' in packed full of emotion and whatever the student does, it seems the sister will not be satisfied, resulting in feelings of distress. The student is physically exhausted and questions her ability to remain standing. She denies wearing a 'professional face' suggesting that she is being 'herself' and displaying patience and kindness, two of her own personal characteristics.

"Professional face!" though I feel defeated

I keep wearing the professional face

The overly interested tone of voice

Keep listening and listening and listening.

Thirteen hours and forty minutes later

I'm not sure if my feet are still at the end of my legs

I'm not sure I have legs

I'm not sure how I'm still standing

And smiling

While I wipe the urine splashes off my shoes

Again

Sister, never happy, what did I do now?

"student" aka "skivvy"

Twenty minutes; I can make it

Call bell

I hear it in my sleep

All the nurses are in handover

"Student! Call bell! Bed 4!"

I have a name, and so does "bed 4!"

She's crying. She's in pain.

I can't help, I need a qualified nurse to dispense the drugs

I wait with her

"give me five minutes" the nurse says 
I've got twenty left... a nurses minute is very long

I'm going to be here late again...

I talk to her. I hold her hand

She tells me stories of times of old

The same joke four times

I laugh every time like it was the first

Because to her it was

She looks delighted that I enjoyed it

She's forgotten her pain

The nurse arrives

The drugs are given

She squeezes my hand and thanks me

I'm a lovely young lass she says

She settles into bed

Ten minutes since I should have finished

I don't mind

I wouldn't have dreamed of leaving her

I walk out of the door and slump

My face stops smiling; take off my "professional face"

The muscles hurt

I remember her joke

I smile to myself

That wasn't my professional face

That was me

That's why I'm coming back tomorrow...

\section{Discussion}

The aim of this study was to explore student nurses experiences of compassion fatigue using poetry as a source of data. It was evident from the poems that the students do suffer from compassion fatigue, based on definitions of the concept suggested in a nursing context by Sabo [43] and in more generally by Figley CR [10].

The data suggests that students feel distressed in clinical practice. This is based on the events they witness and might be due to their novice status, in that they lack knowledge and ability to manage their feelings. Some of the data revealed a frustration that in spite of all of the studying and academic work, the situations still do not make sense to students. Feelings of incompetence can be extremely stressful for students [15] and can impact negatively on their learning. Students describe feelings of sadness and the need to become tougher in order to deal with the situations they encounter. Through the data it is evident that even though students do not have overall responsibility for the care of patients, lack of knowledge and inability to cope with situations is stressful in itself. Indeed some of the most common stressors reported among student nurses include having to watch suffering and the death of patients [4].

Some students referred to their personal characteristics when exploring the care they provided to others. Some of the data articulated the difference between the students 'real' face and their 'professional' one. At times the authors suggest that the caring was 'real', and not just because of wearing a 'professional face'. At times it seemed that the students cared more for the patients than they did for themselves, as they became more and more involved in the challenging situations which led them to place high expectations on themselves. This occurred, for example, in practical ways, such as staying on a shift after it had finished and in emotional ways, such as displaying a 'brave face' in order to comfort a patient. Self-sacrificing behaviours have been shown to be a contributing factor to compassion fatigue [1] and attention needs to be given to enhance students' wellbeing and resilience during their clinical placement [29]. The development of resilience might be beneficial in reducing the risk of compassion fatigue [22]. This might be supported through mindfulness techniques, which could be beneficial in increasing both resilience and self-care and serve as a protective factor [13].

The influences of the work environment and colleagues' attitudes to students were reflected in some of the data. An example of this was when a student felt she was not being taken seriously, was not supernumerary and that other staff members were treating her in an inferior way. Student nurses are required to have supernumerary status during all practice learning in the UK [36] and if this does not happen then they do not have time, under direct supervision, to develop the skills and competence required to qualify as a nurse [49]. Educators in the practice setting are important 'role models for learning to care' and this is facilitated in ways such as reflective practice and sharing experiences ([46], p235). However educators might not have time for joint reflection and subsequent discussion, and can often be too busy to support students learning [33]. Students report that they are often belittled in clinical practice and made to feel like a nuisance to qualified staff [45]. Staff behaviours can leave students feelings helpless and isolated and a difficult environment, combined with lack of support from educators, can lead to students becoming at risk of compassion fatigue.

Apart from poor interpersonal relationships, which are stressful in themselves, the work environment can cause students problems in other ways. Some of the data in this study suggests a 'cure over care' ethos in the UK National Health Service (see for example, the poem 'More') which leads to feelings of stress in student nurses. Students do not feel able to discuss the reasons for the practices they witness or make suggestions for changes in the way care is delivered [18]. Completing tasks is important for learning although it has been suggested that a more task-orientated approach is favoured generally in nursing practice [50]. This can be problematic as students value the emotional connections they make with patients [21]. Students can be left feeling frustrated as 
the reality differs of clinical work differs markedly from what they had envisaged, indeed, students hopes are often challenged as early as their first clinical placement [2].

All of the poems in this sample were written in first person and utilised metaphor to assist in the description of feelings. Using metaphor can support the development of intuition as it reaches beyond the rational mind to enable us to make a broader meaning out of our experiences [9]. This has the potential to be beneficial to student nurses, and support them to make sense of traumatic events. Conversely writing in first person might lead to more negative outcomes such as depression [41]. Writing about events from a distance assists in processing what has happened in an abstract way and on the reason why the writer is feeling distress rather than what they are actually feeling [27]. This could support healthy coping, a reduction in stress and a potential protective effect against compassion fatigue. Discussing feelings which arise from relationships with patients and carers help nurses to understand they are not alone in their experiences, [28] and sharing poetry can provide a way to facilitate this emotional exploration [20].

\section{Limitations}

Data was restricted to one UK University and consisted of a small homogenous sample of all female, white student nurses. However the findings support in depth understanding of the ways in which student nurses experience compassion fatigue, and this has resonance in wider national and international settings.

\section{Conclusion}

The overarching aim of this work was to explore student nurses experiences of compassion fatigue during their clinical placement. There is a drive in the UK towards the development of a more compassionate workforce. However the negative and stressful effects of caring need to be understood, if students are going to be supported in this difficult aspect of their role. It is clear from this study that students feel vulnerable and psychologically distressed by what they witness and it is not always clear that they are supported in making sense of their experiences. One way to explore difficult practice issues might be through reflective poetry writing, which enables students and educators to share experiences in a meaningful way. In order to promote healthy coping, it is important that educators recognise student's susceptibility to compassion fatigue and provide appropriate support.
Funding

No funding was obtained to complete this study.

Availability of data and materials

All data can be viewed at www.caringwords.mmu.ac.uk.

\section{Author's contributions}

$\mathrm{KJ}$ is the sole author of this work.

\section{Author's information}

Dr Kirsten Jack (RN, PhD) is Reader of Learning \& Teaching Development at Manchester Metropolitan University. Her contribution to teaching, learning and research is supported by a clinical career in adult nursing where she specialised in primary care nursing, before embarking on her academic career. She is committed to excellence in teaching and learning and was awarded an UK Higher Education Academy National Teaching Fellowship in 2014. She has a keen interest in pedagogical research specifically the use of the arts to support nurses' emotional self-awareness development. She led on the development of a website www.caringwords.mmu.ac.uk which encourages health care professionals to write reflective poetry, as way to explore their thoughts and feelings about clinical practice.

\section{Competing interests}

The author declares she has no competing interests.

\section{Consent for publication}

Consent is obtained on submission of the students work.

\section{Ethics approval and consent to participate}

Ethical approval was gained from the University ethics committee. On submission of their poems to the Caring Words website, students give their consent for their poem to be used for research and publication purposes. Students are offered the opportunity to be acknowledged as the author of their poem, although none of our students took this up.

Received: 1 November 2016 Accepted: 5 January 2017

Published online: 19 January 2017

\section{References}

1. Abendroth $M$, Flannery J. Predicting the risk of compassion fatigue: A study of hospice nurses. J Hosp Palliat Nurs. 2006;8(6):346-56.

2. Barkley A. 'Ideals, expectations and reality: Challenges for student midwives.' British Journal of Midwifery. 2011. doi: http://dx.doi.org/10.12968/bjom.2011. 19.4.259.

3. Biley FC, Champney-Smith J. "Attempting to say something without saying it...": writing haiku in health care education. Medical Humanities 2003. doi: 10.1136/mh.29.1.39.

4. Burnard P, Edwards, Bennett $K$, Thaibah $H$, Tothova V, Baldacchino D, Bara P, Mytevelli J. A comparative, longitudinal study of stress in student nurses in five countries: Albania, Brunei, the Chez Republic, Malta and Wales Nurse Education Today. 2008. doi: 10.1016/j.nedt.2007.04.002.

5. Cho J, Trent A. Validity in Qualitative Research Revisited. Qual Res. 2006. doi: 10.1177/1468794106065006

6. Dahlberg K, Dahlberg H, Nystrom M. Reflective Lifeworld Research. 2nd ed. Sweden: Studentlitteratur; 2008.

7. Davis C. Poetry about patients: Hearing the nurse's voice. J Med Humanit. 1997. doi:10.1023/A:1025629500471.

8. Department of Health. NHS Bursary Reform. Department of Health. 2016. https://www.gov.uk/government/publications/nhs-bursary-reform/nhsbursary-reform. Accessed 4 Oct 2016.

9. Fox J. Poetic Medicine: The Healing Art of Poem-Making. New York: Putnam; 1997.

10. Figley CR. Compassion Fatigue: Coping with secondary traumatic stress disorder in those who treat the traumatised. New York: Brunner/Mazel; 1995. p. 7.

11. Finlay L. 'Outing' the researcher: the provenance, process and practice of reflexivity. Qual Health Res. 2002. doi:10.1177/104973202129120052.

12. Foster W, Freeman E. Poetry in general practice education: perceptions of learners. Fam Pract. 2008. doi:10.1093/fampra/cmn034.

13. Foureur M, Besley K, Burton G, Yu N, Crisp J. Enhancing the resilience of nurses and midwives: Pilot of a mindfulness based program for increased 
health, sense of coherence and decreased depression, anxiety and stress. Contemp Nurse. 2013. doi:10.5172/conu.2013.45.1.114.

14. Gadamer H. Truth and Method London: Sheed and Ward. 1960

15. Gorostidi XZ, Egilegor XH, Erice MJA, Iturriotz MJU, Garate IM, Lasa MB, Cascante XS. Stress sources in nursing practice. Evol During Nurs Train Nurse Educ Today. 2007. doi:10.1016/j.nedt.2006.10.017.

16. Hamshire C, Willgoss T. The placement was probably the tipping point'-the narratives of recently discontinued students Nurse Education in Practice 2012. 2012. doi:10.1016/j.nepr.2011.11.004

17. Heidegger M. Being and Time MacQuarrie J and Robinson E translation New York: Harper and Row. 1926/1962.

18. Henderson A, Cooke M, Creedy DK, Walker R. Nursing students' perceptions of learning in practice environments: A review Nurse Education Today. 2012. doi:10.1016/.nedt.2011.03.010

19. Husserl E. Logical Investigations Findlay J translation New York; Humanities Press. 1913/1970.

20. Jack K, Tetley J. Using poems to explore the meaning of compassion to undergraduate nursing students. Int Pract Dev J . 2016. doi:10.19043/ipdj.61.004.

21. Jack K, Wibberley C. The meaning of emotion work to student nurses: A Heideggerian Analysis. Int J Nurs Stud. 2013. doi:10.1016/j.jinurstu.

22. Jackson D, Firtko A, Edenborough M. Personal resilience as a strategy for surviving and thriving in the face of workplace adversity. Lit Rev J Adv Nurs. 2007. doi:10.1111/j.1365-2648.2007.04412.x

23. Joinson C. Coping with Compassion Fatigue. Nursing. 1992;4(22):116-21.

24. Khater W, Akhu-Zaheya L, Shaban I. Sources of stress and coping behaviours in clinical practice among Baccalaureate nursing students. Int J Humanit Soc Sci. 2014. doi:10.1016/j.nepr.2012.01.005.

25. Kidd L, Tusaie K. Disconfirming beliefs: the use of poetry to know the lived experience of student nurses in mental health clinical. Issues Ment Health Nurs. 2004;25(4):403-14.

26. Killam L, Heerschap C. Challenges to student learning in the clinical setting: A qualitative descriptive study. Nurse Educ Today. 2013. doi:10.1016/j.nedt. 2012.10.008

27. Kross E, Adyuk O, Mischel W. When asking 'why' does not hurt: Distinguishing rumination from reflective processing of negative emotions. Psychol Sci. 2005. doi:10.1111/j.1467-9280.2005.01600.x.

28. Lally RM. Oncology nurses share their experiences with bereavement and self-care. ONS News. 2005;20(10):4-5.

29. Levett-Jones T, Pitt V, Courtney-Pratt H, Harbrow G, Rossiter R. What are the primary concerns of nursing students as they prepare for and contemplate their first clinical placement experience?. Nurse Education in Practice. 2015; 15(4):304-9.

30. Lopez K, Willis D. Descriptive versus interpretive phenomenology: their contributions to nursing knowledge. Qual Health Res. 2004. doi:10.1177/ 1049732304263638.

31. Maben J, Peccei R, Adams M, Robert G, Richardson A, Murrells T, Morrow E. Patients experiences of care and the influence of staff motivation, affect and wellbeing. Final Report. NIHR Service Delivery and Organisation Programme. 2012. http://www.nets.nihr.ac.uk/_data/assets/pdf_file/0007/85093/ES-081819-213.pdf. Accessed 4 Oct $201 \overline{6}$.

32. Mackintosh C. Caring: the socialisation of pre-registration student nurses: a longitudinal qualitative descriptive study. International Journal of Nursing Studies 2006: doi: http://dx.doi.org.ezproxy.mmu.ac.uk/10.1016/j.jinurstu. 2005.11.006

33. McGowan B. Who do they think they are? Undergraduate perceptions of the definition of supernumerary status and how it works in practice. J Clin Nurs. 2006. doi:10.1111/j.1365-2702.2005.01478.x.

34. Michalec B, Diefenbeck C, Mahoney M. The calm before the storm? Burnout and compassion fatigue among undergraduate nursing students. Nurse Educ Today. 2013. doi:10.1016/j.nedt.2013.01.026.

35. Mohammadian Y, Shahidi S, Mahaki B, Mahammadi AZ, Baghban AA, Zayeri F. Evaluating the use of poetry to reduce signs of depression, anxiety and stress in Iranian female students. Arts Psychother. 2011. doi:10.1016/j.aip. 2010.12.002

36. Nursing and Midwifery Council (NMC). Standards for pre-registration nurse education. London: NMC. 2010

37. Pryjmachuk S, Richards DA. Predicting stress in pre-registration nursing students. Br J Health Psychol. 2007. doi:10.1348/135910706X98524.

38. Rolfe G, Gardner L. Towards a nursing science of the unique: evidence, reflexivity and the study of persons. J Res Nurs. 2005. doi:10.1177/ 174498710501000306
39. Royal College of Nursing. Beyond Breaking Point? RCN. 2013. https://www. rcn.org.uk/professional-development/publications/pub-004448. Accessed 4 Oct 2016.

40. Royal College of Nursing. Response to student bursaries Royal College of Nursing. 2016. https:/www.rcn.org.uk/-/media/royal-college-of-nursing/ documents/.../005689.pdf. Accessed 4 Oct 2016

41. Rude SS, Gortner EM, Pennebaker JW. Language use of depressed and depression-vulnerable college students. Cognit Emot. 2004. doi:10.1080/ 02699930441000030

42. Rudman A, Gustaffson JP. Early career burnout among new graduate nurses: a prospective observational study of intra-individual change trajectories. Int J Nurs Stud. 2011. doi:10.1016/j.jinurstu.2010.07.012.

43. Sabo B. Reflecting on the Concept of Compassion Fatigue. Online J Issues Nurs. 2011. doi:10.3912/OJIN.Vol16No01Man01.

44. Shapiro J, Stein H. Poetic Licence: Writing Poetry as a Way for Medical Students to Examine their Professional Relational Systems. Fam Syst Health. 2005. doi:10.1037/1091-7527.23.3.278

45. Shipton $\mathrm{S}$. The process of seeking stress-care: coping as experienced by senior baccalaureate nursing students in response to appraised clinical stress. J Nurs Educ. 2002;42(6):243-56.

46. Smith PA, Gray B. Reassessing the concept of emotional labour in student nurse education: role of link lecturers and mentors in a time of change. Nurse Educ Today. 2001. doi:10.1054/nedt.2001.0541.

47. Speare J, Henshall A. 'Did anyone think the trees were students?' Using poetry as a tool for critical reflection. Reflective Pract: Int Multidisciplinary Perspect. 2014. doi:10.1080/14623943.2014.944138.

48. Threlfall S. Poetry in action (research). An innovative means to a reflective learner in higher education (HE). Reflective Pract: Int Multidisciplinary Perspect. 2013. doi:10.1080/14623943.2013.767232.

49. Veeramah $\mathrm{V}$. What are the barriers to good mentoring? Nursing Times. 2012; https://www.nursingtimes.net/roles/nurse-managers/what-are-thebarriers-to-good-mentoring/5049649.article. Accessed 4 Oct 2016.

50. Williams A. Hochschild (2003)-the managed heart: the recognition of emotional labour in public service work. Nurse Education Today. 2013. doi: http://dx.doi.org/10.1016/j.nedt.2012.07.006.

51. Yoder EA. Compassion fatigue in nurses. Appl Nurs Res. 2010. doi:10.1016/j. apnr.2008.09.003.

\section{Submit your next manuscript to BioMed Central and we will help you at every step:}

- We accept pre-submission inquiries

- Our selector tool helps you to find the most relevant journal

- We provide round the clock customer support

- Convenient online submission

- Thorough peer review

- Inclusion in PubMed and all major indexing services

- Maximum visibility for your research

Submit your manuscript at www.biomedcentral.com/submit
) Biomed Central 